\title{
Effect of a xylitol and fluoride containing toothpaste on the remineralization of human enamel in vitro
}

\author{
Hiroshi Sano ${ }^{1)}$, Syozi Nakashima ${ }^{2)}$, Yupin Songpaisan ${ }^{3)}$ \\ and Prathip Phantumvanit ${ }^{3)}$ \\ ${ }^{1)}$ Product Development Department, International Division, Lion Corporation, Tokyo, Japan \\ ${ }^{2)}$ Oral-care Research Laboratories, Lion Corporation, Kanagawa, Japan \\ ${ }^{3)}$ Faculty of Dentistry, Thammasat University, Rangsit Campus Pathum Thani, Thailand
}

(Received 13 November 2006 and accepted 9 February 2007)

\begin{abstract}
The aim of this study was to examine the effect of a fluoride and xylitol containing toothpaste on the remineralization of human enamel using Quantitative Light-induced Fluorescence (QLF). Human extracted teeth were cut longitudinally into three or four parts, and artificial subsurface lesion windows $(2 \mathrm{~mm} \times 3 \mathrm{~mm})$ were created by immersion in demineralizing solution. Each enamel sample $(n=$ 7) was treated for $3 \mathrm{~min}$ at $25^{\circ} \mathrm{C}$ twice a day for consecutive 14 days with the slurry of a silica-based toothpaste 1) without $\mathrm{F}^{-}$and xylitol (blank), 2) with 500 ppm $\mathrm{F}^{-}$and 3 ) with $500 \mathrm{ppm}^{-}$and $5 \%$ xylitol toothpaste. In addition, we measured the remineralization ability of a commercially available toothpaste 4) with $500 \mathrm{ppm} \mathrm{F}^{-}$. The average fluorescence loss $\mathrm{F}(\%)$ and lesion size $\left(\mathrm{mm}^{2}\right)$ were determined with $Q L F$. Another variable, delta $Q$, which was defined as the fluorescence loss integrated over the lesion size $\left(\%, \mathrm{~mm}^{2}\right)$, was calculated. The results showed that the combination of $500 \mathrm{ppm} \mathrm{F}^{-}$and $5 \%$ xylitol toothpaste significantly $(P<0.05)$ recovered both the size and delta $Q$ compared to the other groups. These findings suggested that inclusion of xylitol in fluoride toothpaste might be useful to enhance the remineralization in vivo. (J. Oral Sci. 49, 67-73, 2007)
\end{abstract}

\footnotetext{
Correspondence to Dr. Hiroshi Sano, Product Development Department, International Division, Lion Corporation, 3-7 Honjo, 1-Chome, Sumida-ku, Tokyo 130-8644, Japan

Tel: +81-3-3621-6033

Fax: +81-3-3621-6048

E-mail: hirosano@lion.co.jp
}
Keywords: xylitol; fluoride; remineralization; QLF; toothpaste.

\section{Introduction}

A decline in the incidence of dental caries has long been reported in western countries. This was achieved not only by dental health education but also prevention programs involving the utilization of agents like fluoride. Fluoride is a naturally occurring mineral that is very effective in protecting teeth against decay and strongly reduces enamel demineralization, while fluoride ions also enhance remineralization. Therefore, topically applied fluoridated products like toothpaste and mouthwash are most likely responsible for the decreased prevalence of enamel caries.

Xylitol is a pentol employed for many years as a nonacidogenic sweetener in numerous applications. A major aspect of xylitol is that it cannot be fermented by plaque bacteria. The caries inhibiting effect of xylitol has so far been demonstrated by its ability to inhibit the growth and metabolism of the mutans group of streptococci and dental plaque. Xylitol containing products including toothpaste, gum and mouth rinse have shown anticaries properties (14), possibly due to the effects of xylitol on plaque formation, microorganisms, salivary secretion and composition, and on enamel lesions.

Some researchers indicated that xylitol might be involved in the enamel de- and remineralization processes by acting as a $\mathrm{Ca}^{2+}$ carrier required for remineralization (5-7). It has also been shown that a combination of fluoride and xylitol is more effective against caries than fluoride alone (812). However, the extent of the benefit of xylitol in 
combination with fluoride in topical oral products, such as toothpaste, is not clear with respect to the remineralization process.

The aim of this study was to determine the combined effect of xylitol (5\%) and fluoride (500 ppm) in toothpaste on in vitro enamel remineralization using the QLF (Quantitative Light-Induced Fluorescence) method (13).

\section{Materials and Methods}

\section{Toothpaste samples}

Four kinds of toothpaste samples with the following formulations were used: 1) without $\mathrm{NaF}$ and xylitol (blank), 2) $500 \mathrm{ppm} \mathrm{F}^{-}(\mathrm{NaF})$, 3) $5(\%)(\mathrm{w} / \mathrm{w})$ xylitol with $500 \mathrm{ppm}$ $\mathrm{F}^{-}(\mathrm{NaF})$, and 4$)$ a silica-based commercially available toothpaste containing $500 \mathrm{ppm} \mathrm{F}^{-}(\mathrm{NaF})$. Test toothpastes 1),2) and 3) contained the same silica abrasive and other basic ingredients, e.g., $0.1 \%$ sodium saccharine, $0.9 \%$ sodium lauryl sulfate, $25 \%$ sorbitol, $0.6 \%$ flavor and $3 \%$ propylene glycol. Each toothpaste sample was adjusted to $100 \mathrm{w} / \mathrm{w} \%$ by adding purified water. The $\mathrm{pH}$ value of all the test toothpastes was approximately 7 . None of the toothpaste samples contained any fluorescent ingredient, which would interfere with QLF determination.

Test toothpaste slurries were prepared by suspending 10 $\mathrm{g}$ of toothpaste with $20 \mathrm{~g}$ of deionized water. Toothpaste slurries were prepared immediately prior to tooth surface treatment every morning and afternoon.

\section{Sample preparation and treatment}

Human extracted teeth were cut longitudinally into three or four parts with a water-cooled diamond saw, preserving the natural enamel surface and the surface was slightly polished by sandpaper. Twenty-eight enamel blocks were mounted in an acrylic rod and covered with nail varnish, with a window of about $2 \times 3 \mathrm{~mm}^{2}$. Artificial subsurface lesions were created on each of the tooth surfaces by immersing in a demineralizing solution $\left(\mathrm{CaCl}_{2}\right.$ : $12 \mathrm{mM}, \mathrm{KH}_{2} \mathrm{PO}_{4}: 10 \mathrm{mM}$, Lactic acid: $50 \mathrm{mM}, \mathrm{NaCl}: 100$ $\mathrm{mM}: \mathrm{pH}=4.5$ ) at $37^{\circ} \mathrm{C}$ for 5 days. These blocks with artificial early caries lesions were randomly divided into four groups (for each group, $\mathrm{n}=7$ ), after quantitatively determining the average fluorescence loss $\mathrm{F}(\%)$. These groups were then randomly allocated to one of four treatment groups. After removing the nail varnish, the remineralization process was initiated by applying $1.5 \mathrm{ml}$ of toothpaste slurry for 3 min twice a day at $25^{\circ} \mathrm{C}$ (AM 8:30-10 and PM 4:30-6:00). After each treatment, the enamel blocks were washed with $1.5 \mathrm{ml}$ of deionized water twice. The rest of the day, the enamel blocks were exposed to $1.5 \mathrm{ml}$ of remineralizing solution $\left(\mathrm{CaCl}_{2}: 1.5 \mathrm{mM}\right.$, $\mathrm{KH}_{2} \mathrm{PO}_{4}: 5 \mathrm{mM}$, Acetic acid: $100 \mathrm{mM}, \mathrm{NaCl}: 100 \mathrm{mM}$ :
$\mathrm{pH}=6.5)$ at $37^{\circ} \mathrm{C}$.

\section{Fluorescence image acquisition}

QLF (Quantitative Light-Induced Fluorescence) images of the remineralizing process of all enamel blocks were captured at three, seven and fourteen days during the treatment period. Enamel blocks were exposed to approximately $10 \mathrm{~mW} / \mathrm{cm}^{2}$ of violet-blue light (wavelength: $290-450 \mathrm{~nm}$ ). The images were acquired using a miniature CCD camera kept inside the hand piece through a $520 \mathrm{~nm}$ high-pass filter, transmitting only light at wavelengths over $520 \mathrm{~nm}$ (14). The QLF camera hand piece was fixed at a position that provided optimum illumination of the enamel block surface. Images were then recorded using the image capturing software (QLF patient version 3.0, Inspektor Research systems B.V., Amsterdam, The Netherlands) delivered with the system.

To ensure that images of the tooth surfaces were always captured in the same camera positions and from the same angles, the software uses video-repositioning techniques. The video-repositioning technique displays baseline and live images simultaneously and computes their correlation based on similar geometry of the florescence intensities. Images are recorded in a file when the correlation is higher than 0.98 .

\section{Lesion analysis}

Average fluorescence loss F (\%) and size $\left(\mathrm{mm}^{2}\right)$ of the artificial early caries lesions were determined by QLF. Lesions of human extracted teeth are inhomogeneous and the lesion area varies with time. Thus, not only the fluorescence radiance but also the lesion size must be monitored to follow lesion progression or regression.

Fluorescence radiance levels less than $95 \%$ of reconstructed sound fluorescence radiance levels were considered to be artificial early caries lesions and are shown in gray. Darker shades of gray stand for more fluorescence loss.

The fluorescence loss in the lesion was calculated according to the methods described by de Josselin de Jong et al. (13), by reconstruction of the fluorescence radiance of the surrounding sound enamel, which was assumed to be $100 \%$. Average fluorescence loss $\mathrm{F}(\%)=\left(\mathrm{F}_{\mathrm{SE}}-\mathrm{F}_{\mathrm{DEM}}\right)$ $/ \mathrm{F}_{\mathrm{SE}}$, was calculated. $\mathrm{F}_{\mathrm{DEM}}$ and $\mathrm{F}_{\mathrm{SE}}$ were the mean radiance values at the demineralization area and sound enamel areas, respectively. The lesion size $\left(\mathrm{mm}^{2}\right)$ was defined as the sum of all points within the lesion with fluorescence loss $>5 \%$.

Percent change from baseline for three parameters (Tables 2, 3 and 4) was calculated with the following formula; Percent change $(\%)=(1-$ value at the 
measurement day / value at baseline $) \times 100$.

Another variable, deltaQ $\left(\%, \mathrm{~mm}^{2}\right)$ was defined as the fluorescence loss integrated over the lesion size (15). DeltaQ $\left(\%, \mathrm{~mm}^{2}\right)$ is comparable to the total amount of mineral loss from the lesion as measured with longitudinal micro radiography (14). The value of delta $\mathrm{Q}$ did show a decrease, implying remineralization of the lesion.

\section{Statistical methods}

Statistical analysis of the data was performed using the JMP 5.1 packages (SAS Institute Inc.). Analyses of variance (ANOVA) were employed to analyze the data from toothpaste groups and time points. The mean fluorescence loss, size of the artificial early caries lesion, and delta Q values were measured. Post ANOVA pair wise comparisons of the study groups were performed using Tukey-Kramer HSD test. A significance level of $\alpha=0.05$ was set for comparison of the groups.

\section{Results}

There were no statistically significant differences among the four treatment groups with respect to baseline values for the three QLF parameters (Table1).
According to results of the two-way ANOVA, there were significant differences in relation to toothpaste groups $(P<0.000)$ and time $(P<0.000)$ for the three QLF parameters.

Table 2 shows the results of the $\mathrm{F}$ (fluorescence loss: $\%)$ across the 14-day period in the four toothpaste groups. The results revealed that the $500 \mathrm{ppm} \mathrm{F}^{-}$and $5(\%)(\mathrm{w} / \mathrm{w})$ xylitol group produced the highest change of $47.7 \%$ from baseline. Fig. 1 shows that a significant difference $(P<$ $0.05)$ was observed between the blank and other three groups.

Regarding the size of the artificial caries lesion, Table 3 shows that the $500 \mathrm{ppm} \mathrm{F}^{-}$and 5(\%)(w/w) xylitol group also produced the highest change of $57.5 \%$ in size $\left(\mathrm{mm}^{2}\right)$ from baseline to 14 days compared to all other groups. Fig. 2 reveals that the $500 \mathrm{ppm} \mathrm{F}^{-}$and $5(\%)(\mathrm{w} / \mathrm{w})$ xylitol group significantly $(P<0.05)$ increased the $(\%)$ change of size compared to the other three groups.

Table 4 demonstrates that the $500 \mathrm{ppm} \mathrm{F}^{-}$and $5(\%)(\mathrm{w} / \mathrm{w})$ xylitol group provided the highest change of $77.5 \%$ in delta $\mathrm{Q}\left(\%, \mathrm{~mm}^{2}\right)$ values compared to other groups. Fig. 3 shows that the $500 \mathrm{ppm} \mathrm{F}^{-}$and $5(\%)(\mathrm{w} / \mathrm{w})$ xylitol group significantly $(P<0.05)$ increased the $(\%)$ change of delta

Table 1 Baseline mean values of F: fluorescence loss $(\%)$, Size $\left(\mathrm{mm}^{2}\right)$ and delta Q $\left(\%, \mathrm{~mm}^{2}\right)$

\begin{tabular}{lcccc}
\hline Group & $\mathrm{N}$ & $\mathrm{F}(\%)$ & Size $\left(\mathrm{mm}^{2}\right)$ & $\operatorname{delta} \mathrm{Q}\left(\%, \mathrm{~mm}^{2}\right)$ \\
\hline Blank & 7 & $14.7(1.1)$ & $4.2(0.4)$ & $62.4(9.2)$ \\
$500 \mathrm{ppm} \mathrm{F}$ & 7 & $15.5(2.0)$ & $4.3(0.5)$ & $69.5(14.5)$ \\
$500 \mathrm{ppm} \mathrm{F}^{-}, 5 \%$ Xylitol & 7 & $18.6(2.5)$ & $3.4(0.6)$ & $67.2(17.5)$ \\
$500 \mathrm{ppm} \mathrm{F}^{-11}$ & 7 & $17.4(1.8)$ & $3.2(0.4)$ & $56.4(10.0)$ \\
\multicolumn{1}{c}{ Sig. $^{2)}$} & & N.S. & N.S. & N.S. \\
\hline
\end{tabular}

Data is described as mean (S.E.M.).

1) Commercially available toothpaste

${ }^{2)}$ Significance of ANOVA comparison of baseline means. N.S.; $P>0.05$

Table 2 Percent change from baseline of F (fluorescence loss, \%) among test toothpastes

\begin{tabular}{llrll}
\hline Group & $\mathrm{N}$ & 3-days & 7-days & 14-days \\
\hline Blank & 7 & $8.2(4.9)$ & $19.3(2.3)$ & $18.4(2.3)$ \\
$500 \mathrm{ppm} \mathrm{F}$ & 7 & $19.3(5.1)$ & $29.7(3.7)$ & $31.7(3.4)$ \\
$500 \mathrm{ppm} \mathrm{F}^{-}, 5 \%$ Xylitol & 7 & $15.8(4.6)$ & $34.6(4.5)$ & $47.7(3.8)$ \\
$500 \mathrm{pm} \mathrm{F}^{-1)}$ & 7 & $14.6(1.1)$ & $32.3(4.9)$ & $35.2(3.7)$ \\
\hline
\end{tabular}

Data is described as mean (S.E.M.).

1) Commercially available toothpaste 
$\mathrm{Q}$ value compared to the rest of the toothpaste groups during the 14-day treatment period.

Figures 4, 5 and 6 provide illustrations of the (\%) change of QLF parameters from baseline obtained over the course of the study in the four groups.

Figure 7 presents the visual changes in the fluorescence image of one of the samples treated by toothpaste with 500 ppm $\mathrm{F}^{-}$and 5\% xylitol during the experimental periods. The fluorescence regain was demonstrated by less darkness at the lesion site at the subsequent time points.

\section{Discussion}

Recent investigations suggested that xylitol might be involved in the enamel remineralization and demineralization processes. The effect of xylitol on demineralization was suggested by Arends et al. (16), and Smits and Arends (8) have presented data on the inductive capacity of xylitol in remineralization. Miake et al. (7) also

Table 3 Percent change from baseline of Size $\left(\mathrm{mm}^{2}\right)$ among test toothpastes

\begin{tabular}{|c|c|c|c|c|}
\hline Group & $\mathrm{N}$ & 3-days & 7-days & 14-days \\
\hline Blank & 7 & $5.0(7.6)$ & $11.7(4.9)$ & $15.3(6.7)$ \\
\hline $500 p p m F^{-}$ & 7 & $14.6(4.6)$ & $24.7(7.5)$ & $27.8(5.0)$ \\
\hline $500 \mathrm{ppm} \mathrm{F}-5 \%$ Xylitol & 7 & $14.6(5.1)$ & $49.5(9.0)$ & $57.5(8.8)$ \\
\hline 500ppm $\mathrm{F}^{-1)}$ & 7 & $9.5(2.2)$ & $24.1(4.0)$ & $32.5(6.7)$ \\
\hline
\end{tabular}

Data is described as mean (S.E.M.).

1) Commercially available toothpaste

Table 4 Percent change from baseline of delta $\mathrm{Q}\left(\%, \mathrm{~mm}^{2}\right)$ values among test toothpastes

\begin{tabular}{lllll}
\hline Group & N & 3-days & 7-days & 14-days \\
\hline Blank & 7 & $11.2(10.9)$ & $28.6(4.8)$ & $31.3(5.2)$ \\
$500 p p m F^{-}$ & 7 & $30.2(6.5)$ & $45.6(7.7)$ & $50.5(4.5)$ \\
$500 p^{-}, 5 \%$ Xylitol & 7 & $26.9(7.0)$ & $67.1(5.8)$ & $77.5(5.0)$ \\
500 ppm F $^{-1)}$ & 7 & $22.6(2.3)$ & $48.5(5.0)$ & $56.1(5.8)$ \\
\hline
\end{tabular}

Data is described as mean (S.E.M.).

1) Commercially available toothpaste

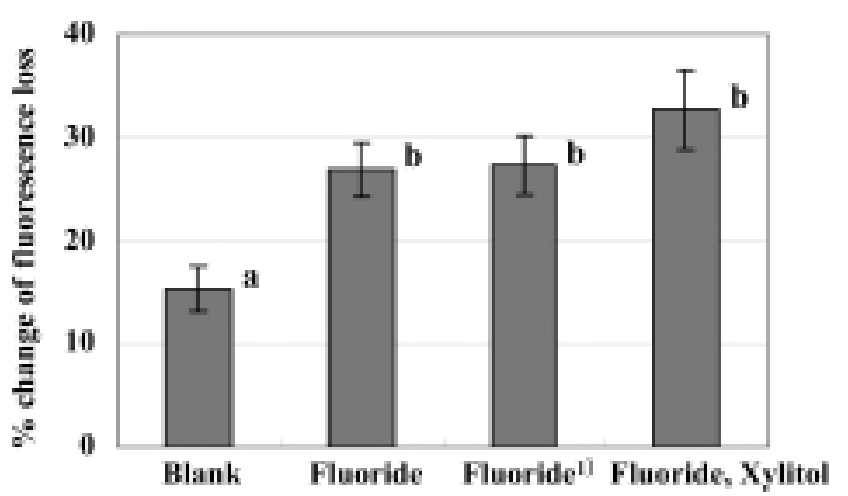

Fig. 1 Percent change of fluorescence loss from baseline in four toothpaste groups. (Mean \pm S.E.M.)

1) Commercially available toothpaste.

Means with different letters are significantly different $(P<0.05)$.

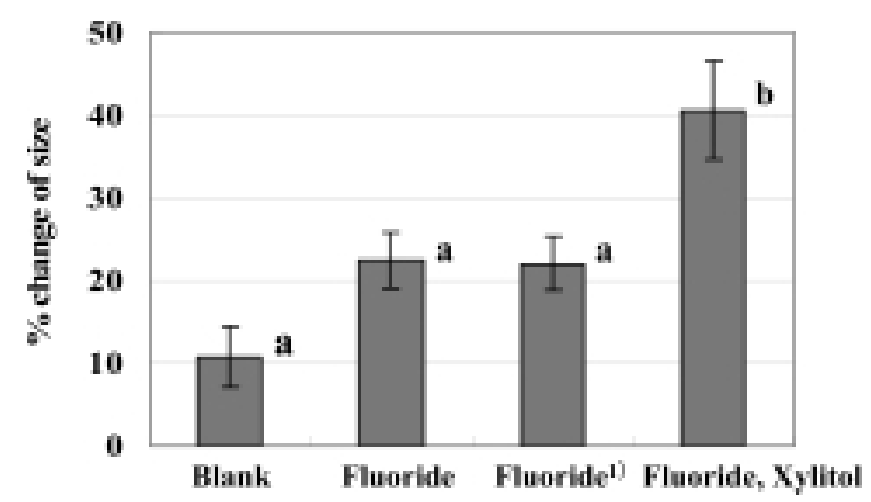

Fig. 2 Percent change of size from baseline in four toothpaste groups. (Mean \pm S.E.M.)

1) Commercially available toothpaste.

Means with different letters are significantly different $(P<0.05)$. 


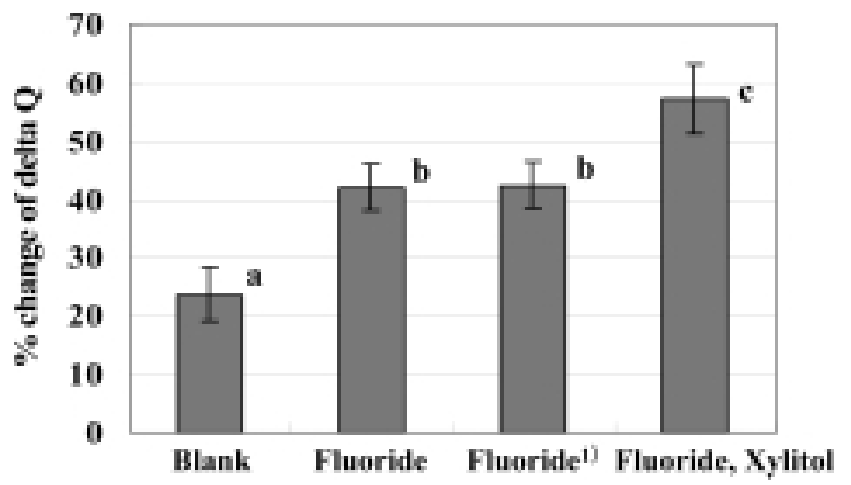

Fig. 3 Percent change of delta $Q$ from baseline in four toothpaste groups. (Mean \pm S.E.M.)

1) Commercially available toothpaste.

Means with different letters are significantly different $(P<0.05)$.

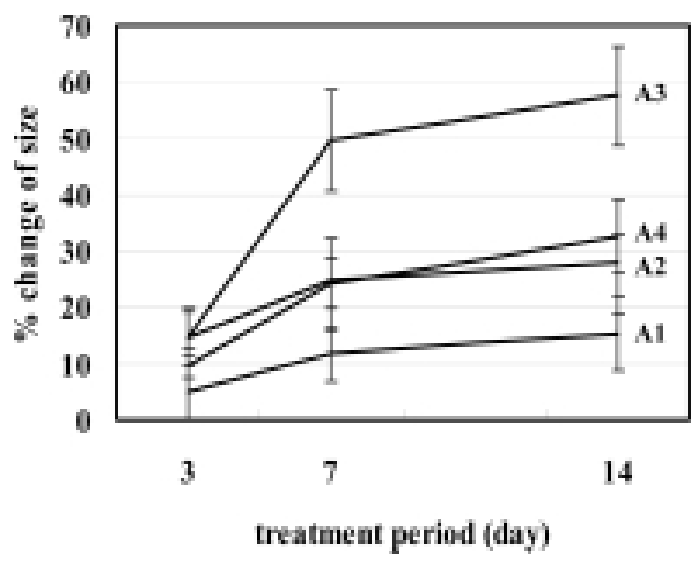

Fig. 5 Illustration of percent change of size $\left(\mathrm{mm}^{2}\right)$ from baseline across the 14-day study. (Mean \pm S.E.M.) A1; Blank, A2; 500ppm F-, A3; 500ppm F- with 5\% xylitol, A4; 500ppm F'; commercially available toothpaste.

Baseline

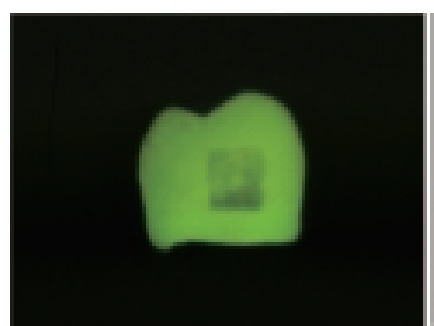

F (\%)

Size $\left(\mathrm{mm}^{2}\right)$

$\operatorname{deltaQ}\left(\%, \mathrm{~mm}^{2}\right)$
18.2

5.6

102 3-days

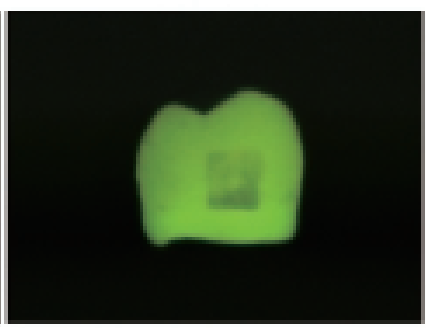

15.7

5.1

80.1

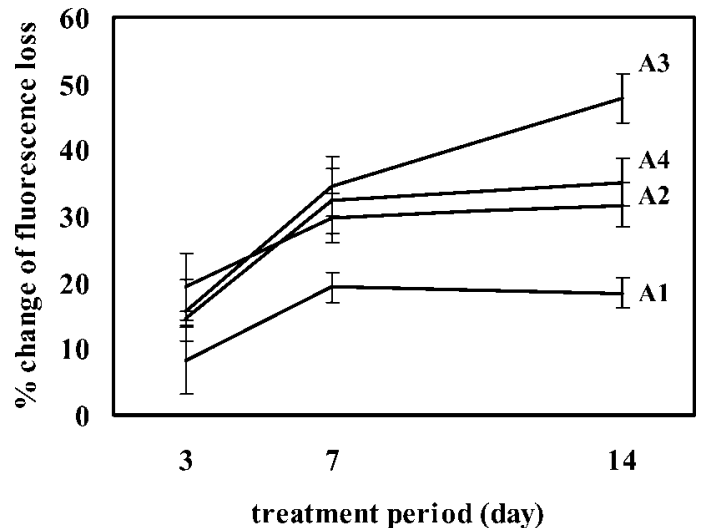

Fig. 4 Illustration of percent change of fluorescence loss (\%) from baseline across the 14-day study. (Mean \pm S.E.M.) A1; Blank, A2; 500ppm F-, A3; 500ppm F- with 5\% xylitol, A4; 500ppm $\mathrm{F}^{-}$; commercially available toothpaste.

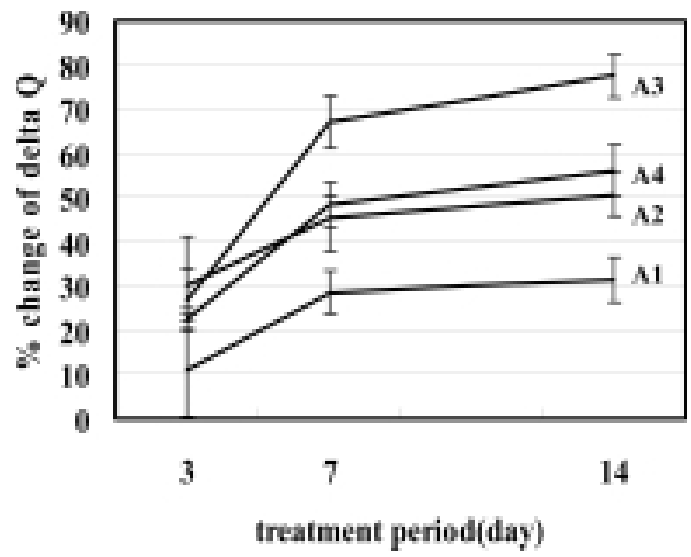

Fig. 6 Illustration of percent change of delta $\mathrm{Q}\left(\%, \mathrm{~mm}^{2}\right)$ from baseline across the 14-day study. (Mean \pm S.E.M.) A1; Blank, A2; 500ppm F-, A3; 500ppm F' with 5\% xylitol, A4; 500ppm $\mathrm{F}^{-}$: commercially available toothpaste.

7-days

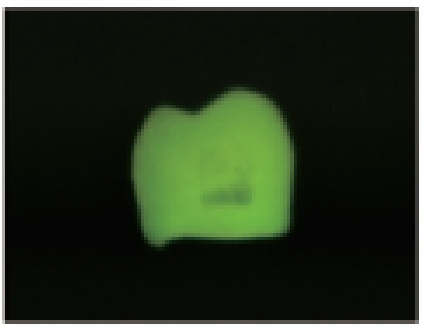

11.9

3.1

36.9 14-days

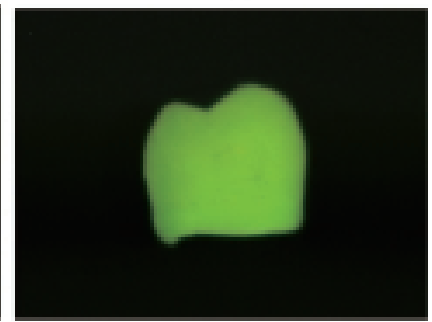

6.7

1.8

12.1

Fig.7. Changes in the fluorescence image of the experimental area of a human enamel specimen treated by toothpaste with 500 ppm $\mathrm{F}^{-}$plus $5 \%$ xylitol during the remineralization period. 
indicated that xylitol can induce the remineralization of deeper layers of demineralized enamel by facilitating $\mathrm{Ca}^{2+}$ movement and accessibility. In addition, Amaechi et al. (11) revealed that demineralization is inhibited and remineralization is accelerated when xylitol is used with fluoride.

We examined the effect of fluoride and xylitol containing toothpaste on the remineralization of human enamel using the Quantitative Light-induced Fluorescence (QLF) method. The findings demonstrated that a slurry of toothpaste with $500 \mathrm{ppm} \mathrm{F}^{-}$plus $5 \%$ xylitol showed more enhanced remineralization than without addition of xylitol to toothpastes. The degree of remineralization was determined by the difference in average fluorescence loss $\mathrm{F}(\%)$, size $\left(\mathrm{mm}^{2}\right)$ and delta $\mathrm{Q}\left(\%, \mathrm{~mm}^{2}\right)$ of artificial early caries lesions. Significant differences were apparently observed in both delta $\mathrm{Q}\left(\%, \mathrm{~mm}^{2}\right)$ and size $\left(\mathrm{mm}^{2}\right)$, and another parameter, average fluorescence loss, showed similar remineralization trends graphically (Figs. 4-6).

Gaffar et al. (9) demonstrated that the combination of $10 \%$ xylitol and 1,100 $\mathrm{ppm} \mathrm{F}^{-}(\mathrm{NaF})$ toothpaste was significantly more effective than fluoride itself for cariostatic effects in rats. Moreover, they showed that the combination provided significantly more remineralization of dentine than fluoride alone in situ. These findings are partially in line with our results and also supported the usefulness of the combination of xylitol and fluoride in toothpaste.

In our pilot study, toothpaste with $500 \mathrm{ppm} \mathrm{F}^{-}$with $0.1 \%$ xylitol did not show any high remineralization ability compared to toothpaste with $500 \mathrm{ppm} \mathrm{F}^{-}$. This means that a certain concentration of xylitol is required to provide a remineralization effect.

Although the 5\% addition of xylitol to the toothpaste may appear somewhat low when compared to the concentration (20-25\%) used by Amaechi et al. $(10,11)$, we showed that toothpaste with $500 \mathrm{ppm} \mathrm{F}^{-}$plus $5 \%$ xylitol had a more improved remineralization effect than without addition of xylitol to toothpastes. This observation points towards a possible caries-preventing effect of even lower xylitol concentrations in toothpastes in the actual clinical situation.

Toothpaste usually contains one or more organic polyhydroxy compounds, such as sorbitol, glycerol and propylene glycol, as a humectant. Toothpaste samples prepared in this study contained $25 \%$ of sorbitol. Fukuda et al. (6) examined the possible interaction between xylitol and $\mathrm{Ca}^{2+}, \mathrm{F}^{-}$by using NMR (Nuclear Magnetic Resonance) and suggested that xylitol had an ability to retard $\mathrm{CaF}_{2}$ formation when $\mathrm{Ca}^{2+}$ and $\mathrm{F}^{-}$were present, and this ability was greater than that of sorbitol. These findings supported the possibility that existence of $25 \%$ sorbitol in the toothpaste did not influence the additional remineralization ability of $5 \%$ xylitol.

Regarding the degree of variation in size $\left(\mathrm{mm}^{2}\right)$, the commercially available toothpaste showed relatively low variations compared to those of other test samples in the early stage of the study. The reason for this is unclear, but it might be partially due to the difference in toothpaste ingredients, especially presumed higher amount of foaming agent (sodium lauryl sulfate) and humectants (sorbitol or glycerin). These agents facilitate dispersion and formation of a homogeneous slurry suspension, resulting in a uniform reaction at the remineralization site in artificial early caries lesions.

The average size $\left(\mathrm{mm}^{2}\right)$ at baseline ranged from 3.2 to 4.3 , which was about $50-70 \%$ of the total experimental size $\left(6 \mathrm{~mm}^{2}\right)$. This is due to the relatively moderate demineralization treatment performed in order to create a shallow subsurface of artificial early caries lesions in the present study.

Ando et al. (17) mentioned that in a time course study, one of the disadvantages in evaluating average fluorescence loss $\mathrm{F}(\%)$ or size $\left(\mathrm{mm}^{2}\right)$ independently is that a value for F (\%) may be maintained even if the size of the lesion increases or decreases, or the size of lesion may be maintained, although the $\mathrm{F}(\%)$ value increases or decreases. Another disadvantage would be that the lesion may have a large $\mathrm{F}(\%)$ value despite a small size, or it may have a small $\mathrm{F}(\%)$ value despite a large size. To overcome these problems, another variable (delta $\mathrm{Q}$ ) was introduced to evaluate remineralization with QLF (14).

To date, possible small remineralization effects of xylitol and/or fluoride in experiments might be hidden, partially due to biological variations in enamel blocks or relatively larger variation in the value obtained by TMR (transverse micro-radiography) methods. It is important to note that, in conventional work, the TMR method is a 'slice' system; i.e. sections from the early caries lesion are taken. Carious lesions are rarely homogenous even in artificial specimens and therefore there can be section-bias. However, the QLF system analyses the lesion in its entirety and therefore the conclusions drawn are valid (14).

Ericsson and Forsman (18) suggested that toothpastes with either sodium fluoride $(\mathrm{NaF})$ or sodium monofluorophosphate (MFP) should contain less than $0.1 \% \mathrm{~F}^{-}$, if used by children of tooth-mineralizing age. Since $\mathrm{F}^{-}$in toothpaste is known to have a high bioavailability, the risk of an increase in dental fluorosis is too high; therefore, daily $\mathrm{F}^{-}$intake should be taken into consideration with caution.

Studies designed to test whether efficacy is maintained when toothpaste containing less than $1000 \mathrm{ppm}$ of fluoride 
is used are important because of the potential increased risk of dental fluorosis from use of conventional fluoride toothpaste. Therefore, it is critical to assess what characteristics of fluoride toothpastes may be most suitable for obtaining the maximum effect on dental caries with minimum risk of dental fluorosis.

In conclusion, toothpaste containing $500 \mathrm{ppm} \mathrm{F}^{-}(\mathrm{NaF})$ and $5 \%$ xylitol enhances the remineralization of early caries lesion for a 14-day treatment period compared to toothpastes containing $500 \mathrm{ppm} \mathrm{F}^{-}(\mathrm{NaF})$ in vitro. Although it is not possible to directly correlate the present findings to in vivo situations, toothpaste containing $500 \mathrm{ppm} \mathrm{F}^{-}(\mathrm{NaF})$ and 5\% xylitol might be beneficial, both with respect to its caries inhibiting effect and decrease in the risk of dental fluorosis, in young individuals who are undergoing enamel remineralization.

\section{Acknowledgments}

The authors wish to thank Mr. Takashi Ujiie for his support in conducting this study. They would also like to thank Prof. Karl Kailaya, School of Dentistry, University of Washington, for guiding and assisting in data analyses. The authors express their appreciation to Mr. Yasushi Fukuda and Haruhiko Fujikawa for their help with the QLF analyses.

\section{References}

1. Sintes JL, Escalante C, Stewart B, McCool JJ, Garcia L, Volpe AR, Triol C (1995) Enhanced anticaries efficacy of a $0.243 \%$ sodium fluoride $/ 10 \%$ xylitol/silica dentifrice: 3-year clinical results. Am J Dent 8, 231-235

2. Tanzer JM (1995) Xylitol chewing gum and dental caries. Int Dent J 45, 65-76

3. Suda R, Suzuki T, Takiguchi R, Egawa K, Sano T, Hasegawa K (2006) The effect of adding calcium lactate to xylitol chewing gum on remineralization of enamel lesions. Caries Res 40, 43-46

4. Lingstrom P, Lundgren F, Birkhed D, Takazoe I, Frostell G (1997) Effects of frequent mouthrinses with palatinose and xylitol on dental plaque. Eur J Oral Sci 105, 162-169

5. Mäkinen KK, Söderling E (1984) Solubility of calcium salts, enamel, and hydroxyapatite in aqueous solutions of simple carbohydrates. Calcif Tissue Int 36, 64-71

6. Fukuda Y, Igarashi A, Takayama T, Nakashima S (2000) NMR-analysis on interaction between xylitol and fluoride or calcium. J Dent Res 79, Spec, 557 (abstract)

7. Miake Y, Saeki Y, Takahashi M, Yanagisawa T (2003) Remineralization effects of xylitol on demineralized enamel. J Electron Microsc (Tokyo) 52, 471-476

8. Smits MT, Arends J (1985) Influence of xylitoland/or fluoride-containing toothpastes on the remineralization of surface softened enamel defects in vivo. Caries Res 19, 528-535

9. Gaffar A, Blake-Haskins JC, Sullivan R, Simone A, Schmidt R, Saunders F (1998) Cariostatic effects of a xylitol/NaF dentifrice in vivo. Int Dent J 48, 3239

10. Amaechi BT, Higham SM, Edgar WM (1998) The influence of xylitol and fluoride on dental erosion in vitro. Arch Oral Biol 43, 157-161

11. Amaechi BT, Higham SM, Edgar WM (1999) Caries inhibiting and remineralizing effect of xylitol in vitro. J Oral Sci 41, 71-76

12. Maehara H, Iwami Y, Mayanagi H, Takahashi N (2005) Synergistic inhibition by combination of fluoride and xylitol on glycolysis by mutans streptococci and its biochemical mechanism. Caries Res 39, 521-528

13. de Josselin de Jong E, Sundström F, Westerling H, Tranaeus S, ten Bosch JJ, Angmar-Månsson B (1995) A new method for in vivo quantification of changes in initial enamel caries with laser fluorescence. Caries Res 29, 2-7

14. Al-Khateeb S, Ten Cate JM, Angmar-Månsson B, de Josselin de Jong E, Sundström G, Exterkate RAM, Oliveby A (1997) Quantification of formation and remineralization of artificial enamel lesions with a new portable fluorescence device. Adv Dent Res 11, 502-506

15. van der Veen MH, de Josselin de Jong E (1999) The introduction of a new parameter $\Delta \mathrm{Q}$ for incipient caries measurement with QLF. Caries Res 33, 318 (abstract)

16. Arends J, Christoffersen J, Schuthof J, Smits MT (1984) Influence of xylitol on demineralization of enamel. Caries Res 18, 296-301

17. Ando M, Eckert GJ, Stookey GK, Zero DT (2004) Effect of imaging geometry on evaluating natural white-spot lesions using quantitative light-induced fluorescence. Caries Res 38, 39-44

18. Ericsson Y, Forsman B (1969) Fluoride retained from mouthrinses and dentifrices in preschool children. Caries Res 3, 290-299 